\title{
ИССЛЕДОВАНИЕ СТРУКТУРЫ НЕЙТРАЛЬНЫХ КИСЛОРОДСОДЕРЖАЩИХ СОЕДИНЕНИЙ ПЕРВИЧНОЙ КАМЕННОУГОЛЬНОЙ СМОЛЫ
}

\author{
(Представил И. Клесмент)
}

Исследование структуры нейтральных кислородсодержащих соединений (НКС), выделенных из смол коксования угля группы Г6 в условиях, исключающих высокотемпературный пиролиз парогазовых продуктов, весьма целесообразно и актуально с точки зрения глубокого изучения строения органической массы ископаемых топлив, установления ее взаимосвязи с растительным материалом, определения форм связи кислорода в угле, распределения его между различными функциональными группами.

Решение поставленных вопросов позволит определить возможные пути термохимических превращений угольной массы и тем самым оптимизировать процессы ее термодеструкции с целью получения максимальных количеств НКС, являющихся ценным сырьем для промышленности основного органического синтеза.

Получение первичной смолы осуществлялось на установке, подробно описанной в [1]. Смола подвергалась групповому анализу с выделением соответствующих групп соединений [2]. Исходные НКС получены методом адсорбционной жидкостной хроматографии на силикагеле марки АCK из нейтрального масла - остатка смолы после выделения из нее органических оснований, карбоновых кислот, фенолов и асфальтенов. Элюент - ацетон. Выход НКС составил 5,5\% (масс. от безводной смолы).

Характеристика молекулярной структуры исходных НКС составлена на основании обобщения данных ИК-, ЯМР- и УФ-спектроскопии, хромато-масс-спектрометрии, подтвержденных результатами элементного и функционального анализов, молекулярной массы, определенной криоскопически по Расту в камфаре.

Установлено, что исходные НКС представляют собой сложную многокомпонентную смесь соединений различных классов с алкилированным гидроароматическим или полностью гидрированным скелетом, замещенным фенольными с ослабленными кислотными свойствами группами, кетонными, алкоксильными, хиноидными, спиртовыми группами, кислород- и азотсодержащими гетероциклами.

С целью разделения исходных НКС на узкие фракции и получения из них индивидуальных соединений были последовательно применены метод экстракции и тонкослойной хроматографии (ТСX). Оба метода весьма «мягки» и не вызывают изменений в структуре исходных компонентов. Условия экстракции стандартизовались. Соотношение НКС и растворителя во всех случаях выдерживалось равным 1:10 (по массе).

Экстракцией были получены из первичных НКС пять фракций (рис. 1). Циклогексановая фракция дополнительно разделялась адсорб- 


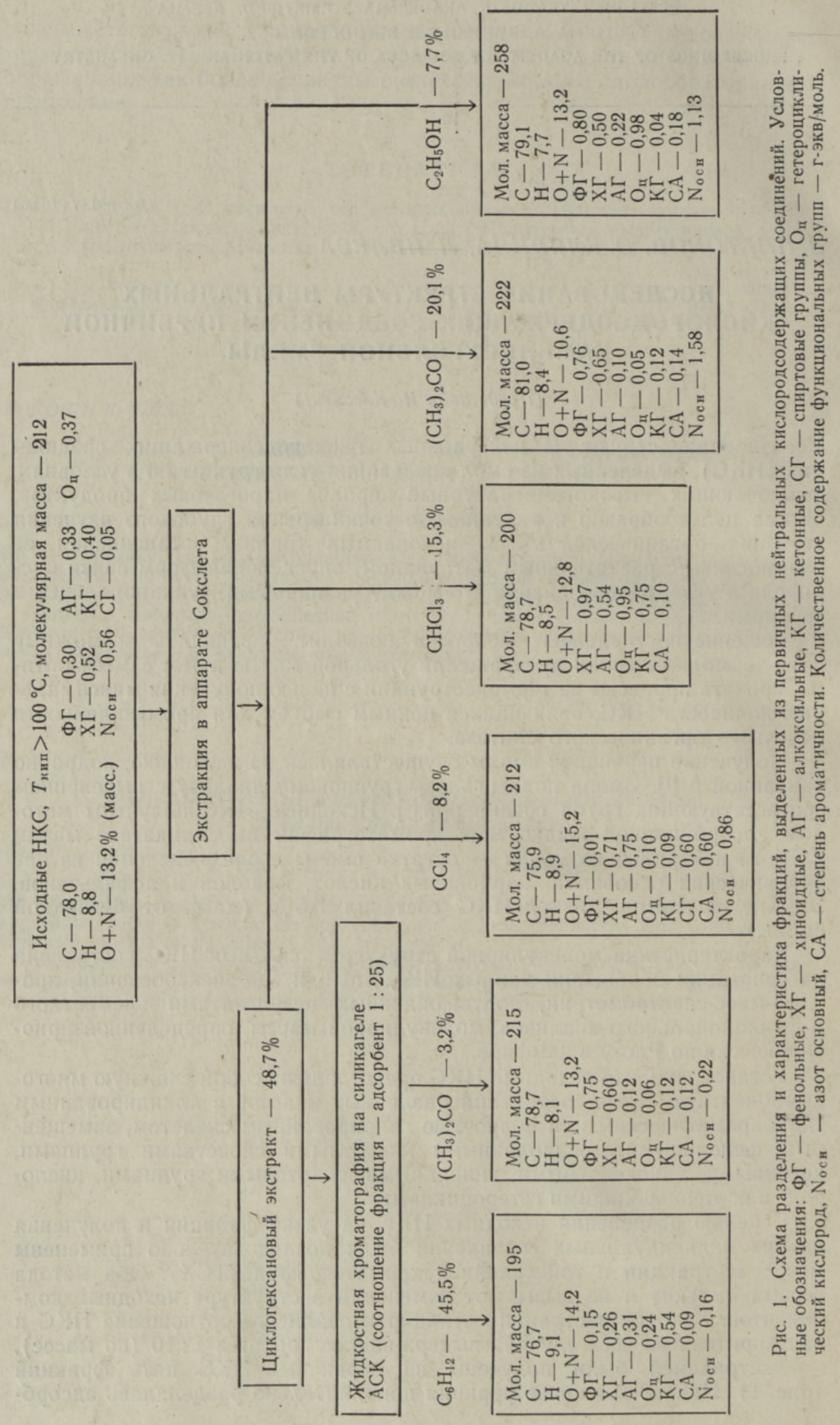


ционной жидкостной хроматографией на силикагеле марки АCK. C помощью гексана и ацетона выделено два элюата.

Сопоставление данных указывает, что с увеличением полярности растворителя, как правило, экстрагируются компоненты с возрастающей молекулярной массой. Степень ароматичности, определенная на основе данных ИК- и ${ }^{1} \mathrm{H}$-ЯМР-спектроскопии, максимальна у $\mathrm{CCl}_{4}$ экстракта - 0,60.

Сравнение результатов функционального анализа (рис. 1) указывает на резкое различие между фракциями. Основная масса фенольных гидроксилов распределяется между ацетоновым элюатом $(0,75$ г-экв/моль), ацетоновым и этанольным экстрактами $(0,76$ и 0,80 г-экв/моль соответственно). Для соединений, извлекаемых хлороформом и четыреххлористым углеродом, эти группы нехарактерны. Максимум содержания хиноидных групп приходится на $\mathrm{CHCl}_{3}$ - и $\mathrm{CCl}_{4}$-экстракты $(0,97$ и 0,71 г-экв/моль соответственно), минимум - у компонентов гексанового элюата $(0,26$ г-экв/моль).

Гетероциклический кислород распределен равномерно между хлороформенной и этанольной фракциями: 0,95 и 0,98 г-экв/моль соответственно, в гексановом элюате его 0,24 г-экв/моль, а в остальных фракциях - менее 0,10 г-экв/моль.

Содержание кетонных групп повышено в хлороформенном экстракте $(0,75$ г-экв/моль) и в гексановом элюате $(0,54$ г-экв/моль) и нехарактерно для других экстрактов.

$\mathrm{CCl}_{4}$-экстракт является единственным, в котором концентрируются спиртовые группы (0,60 г-экв/моль).

Максимальное содержание азотсодержащих функциональных групп отмечено для фракций, извлеченных $\mathrm{CCl}_{4}$, ацетоном и этанолом.

Таким образом, методами экстракции и адсорбционной жидкостной

Таблица 1

Выход, молекулярная масса, элементный, функциональный состав и молекулярная формула компонентов гексанового элюата НКС

\begin{tabular}{|c|c|c|c|c|c|c|c|c|c|c|c|c|c|}
\hline \multirow[b]{2}{*}{ 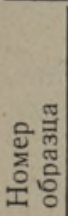 } & \multirow{2}{*}{ 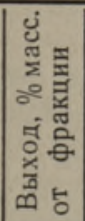 } & \multirow{2}{*}{ 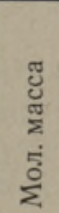 } & \multicolumn{4}{|c|}{$\begin{array}{c}\text { Элементный состав, } \\
\% \text { масс. }\end{array}$} & \multicolumn{6}{|c|}{$\begin{array}{c}\text { Функциональный состав, } \\
\text { г-экв/моль }\end{array}$} & \multirow{2}{*}{$\begin{array}{c}\text { Молекулярная } \\
\text { формула }\end{array}$} \\
\hline & & & C & $\mathrm{H}$ & $\mathrm{O}$ & $\mathrm{N}$ & $\Phi \Gamma$ & $\mathrm{X \Gamma}$ & КГ & $\mathrm{A} \Gamma$ & $\mathrm{O}_{\text {II }}$ & $\stackrel{*}{\circ}$ & \\
\hline
\end{tabular}

1

$2|6,30| 232|77,3|$

3 4, 4 , $240 \quad 73,5$

$\begin{array}{lllll}4 & 2,12 & 234 & 77,2\end{array}$

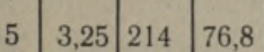

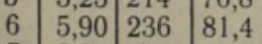

\begin{tabular}{l|l|l|l|l}
7 & 6,01 & 206 & 77,9
\end{tabular}

8 5, $500220 \quad 79,4$

$\begin{array}{lllll}9 & 6,50 & 168 & 72,5\end{array}$

$10 \quad 8,11 \quad 180 \quad 74,4$

$11 \quad 4,24 \quad 218 \quad 77,8$

$\begin{array}{lllll}12 & 9,80 & 220 & 77,0\end{array}$

\begin{tabular}{lll|l}
13 & 5,90 & 202 & 72,4
\end{tabular}

$\begin{array}{lllll}14 & 4,95 & 180 & 75,3\end{array}$

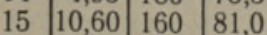

\begin{tabular}{l|l|l|l|}
16 & 6,35 & 209 & 79,8 \\
\hline
\end{tabular}

\begin{tabular}{l|l|l|l|l}
17 & 3,40 & 178 & 73,5 \\
\hline
\end{tabular}

\begin{tabular}{l|l|l|l|l|}
18 & 7,16 & 165 & 86,8 \\
\hline
\end{tabular}
Остатокна старте

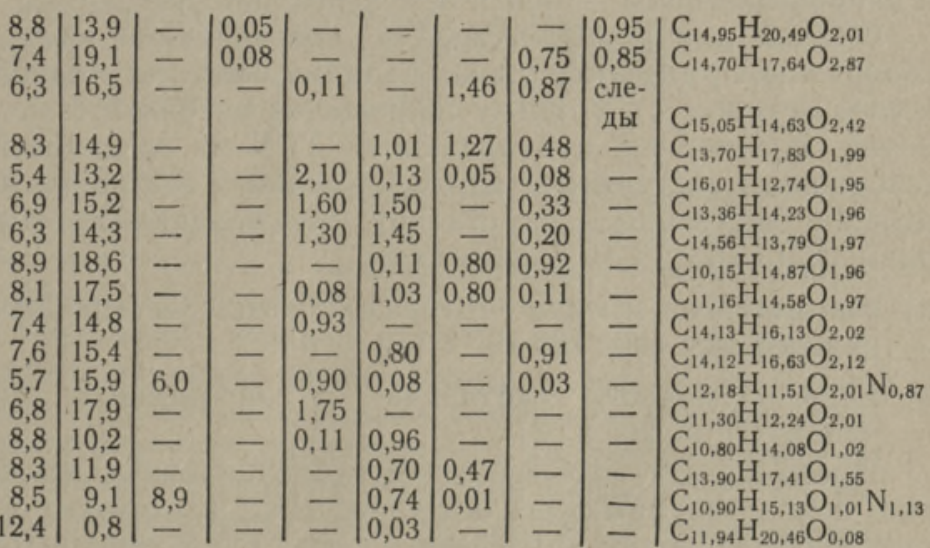

* СЭГ - сложноэфирные групгі. 
Выход, молекулярная масса, элементный, функциональный состав и молекулярная формула компонентов хлороформенного экстракта НКС

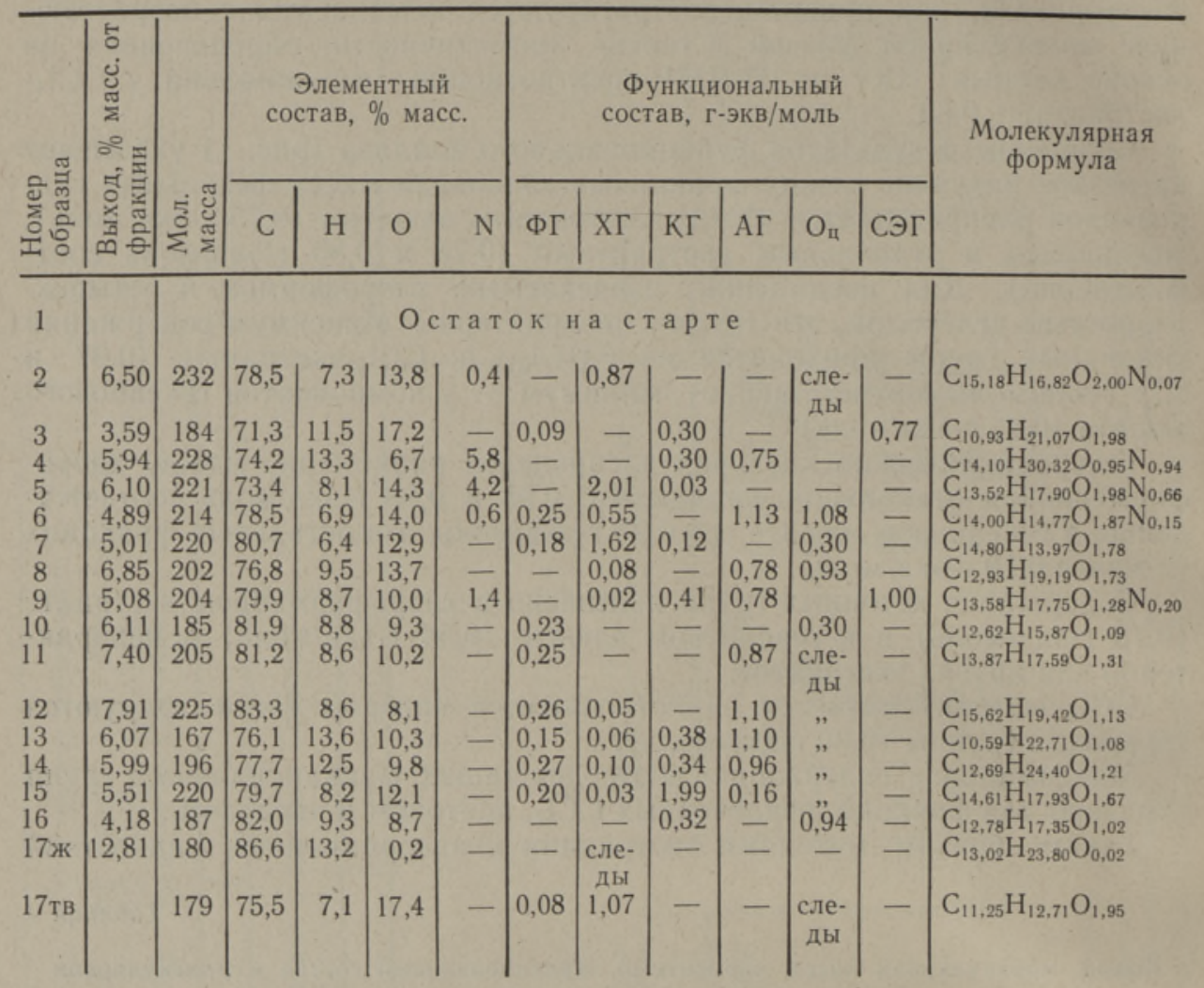

хроматографии удалось разделить исходные НКС на ряд узких фракций, различающихся не только молекулярной массой, но и особенностями структуры, содержанием тех или иных функциональных групп.

ИК- и УФ-спектроскопия экстрактов показала, что некоторые из них различаются преимущественным типом конденсации колец: в этанольном превалируют ангулярно-конденсированные, тогда как в ацетоновом и хлороформенном - почти исключительно линеарные.

Однако для решения задачи, поставленной выше, считалось целесообразным разделить узкие фракции НКС на индивидуальные компоненты методом ТСХ. Ниже приводятся результаты исследования соединений, полученных препаративной ТСX из гексанового элюата циклогексанового экстракта и хлороформенного экстракта. Оптимальное разделение достигалось на стандартных пластинках «Силуфол» (ЧССР) размерами $15 \times 15$ см в системах:

a) гексанового элюата - гексан : бензол : четыреххлористый углерод : : хлороформ $(20: 10: 10: 5)$,

б) хлороформенного экстракта - циклогексан:толуол: этилацетат : : ацетон $(15: 20: 5: 3)$.

Препаративно полученные соединения изучались комплексом методов, использованных для исходных НКС и их узких фракций. Характеристика соединений приведена в табл. 1 и 2, предположительные структурные формулы на рис. 2. 

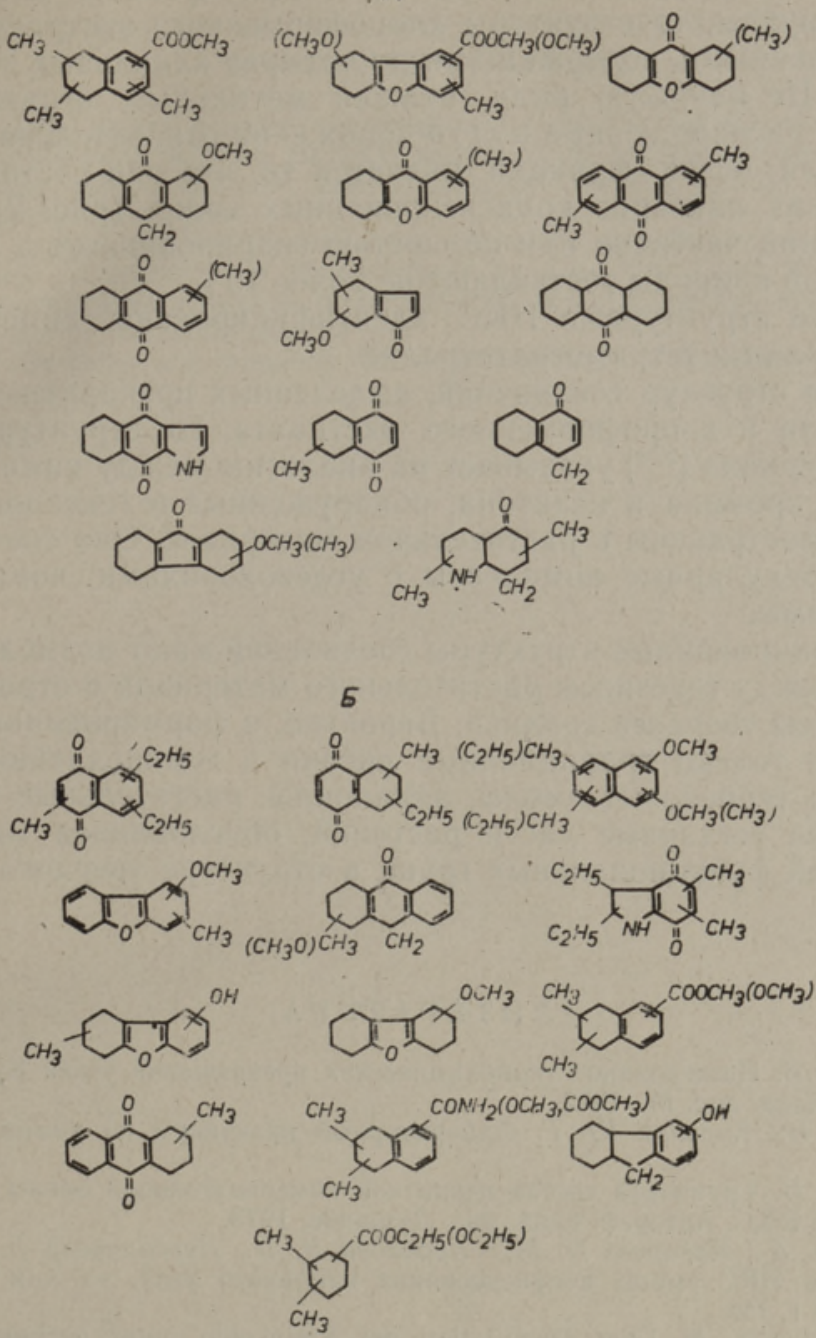

$\mathrm{H}-\mathrm{C}_{7} \mathrm{H}_{15}-\mathrm{O}-\mathrm{C}_{7} \mathrm{H}_{15}\left(\mathrm{NH}_{2}\right) \quad \mathrm{H}-\mathrm{C}_{7} \mathrm{H}_{15}-\mathrm{C}-\mathrm{C}_{7} \mathrm{H}_{15}\left(\mathrm{NH}_{2}\right)$

Рис. 2. Предположительные структурные формулы первичных нейтральных кислородсодержащих соединений: гексановый элюат циклогексанового экстракта (А) и хлороформенный экстракт (Б).

Сравнение данных табл. 1 и 2 показывает, что несмотря на относительно близкие значения молекулярных масс соединения гексанового элюата циклогексанового экстракта и хлороформенного экстракта НКС значительно различаются содержанием отдельных функциональных групп. Особенностью гексанового элюата является высокое содержание соединений, включающих пироновое шестичленное кольцо с гетероциклическим кислородом - производных хромона и ксантона. В то же время в хлороформенном экстракте гетероциклического кислорода мало. Из хиноидных структур в составе гексанового элюата превалируют производные антрахинона, а в хлороформенном экстракте - производные нафтохинона.

Значительные различия между рассматриваемыми фракциями отмечаются в отношении алкильных заместителей. Если в гексановом элюате 
их количество невелико, причем идентифицированы исключительно метильные группы, то структуры хлороформенного экстракта являются высокозамещенными, содержащими до четырех алкильных заместителей в молекуле. Не меньшую роль, нежели метильные, играют этильные заместители, расположенные в орто-положении относительно друг друга.

Общим для обеих фракций является то, что они состоят из би- и трициклических линеарно конденсированных колец (рис. 2). Большинство соединений частично или полностью гидрированные, а компоненты ароматической природы составляют не более $10 \%$.

Наряду со структурами НКС идентифицированы диметилдекалин, триметилдекалин и тетраметилтетралин.

Сравнение структур соединений, выделенных препаративно из гексанового элюата и хлороформенного экстракта, со структурами растительного материала $\left[{ }^{3-5}\right]$ указывает на аналогию между ними. Например, производные хромона и ксантона, обнаруженные в гексановом элюате, широко распространены в растительном материале. Они способны образовывать молекулярные комплексы с углеводородами, поэтому трудно от них отделимы.

Идентифицированные структуры соединений дают возможность углубить связи между генезисом растительного материала и строением органической массы твердого топлива. Вероятно, в формировании последней участвуют не только традиционные лигнин и гемицеллюлоза, воска и липиды, но и терпеновые смолы, алкалоиды, растительные пигменты и многие другие составные части растений, обусловливая многообразие форм и связей функциональных групп в структуре твердого топлива.

\section{ЛИТЕРАТУРА}

1. Платонов В. В. Исследование термохимических превращений углей Кузнецкого бассейна. Канд. дис. М., 1972.

2. Камнева А. И., Королев Ю. Г. Лабораторный практикум по химии топлива. М., 1975.

3. Бурякова Э. П. Групповой состав первичной каменноугольной смолы и химическая природа НКС. Автореф. канд. дис. Душанбе, 1973.

4. Румянцева Э. А., Караваев Н. М., Бурякова Э. П., Передникова З. М. Состав и свойства НКС смолы полукоксования каменного угля. - Хим. тверд. топл., 1973, № 1, 159 .

5. Pictet, A., Bouvier, M. Uber Destillation der Steinkohle unter geringem Druck. Chem. Ber., 1914, 13, 3342-3353.

Тульский государственный

педагогический институт

Поступила в редакцию

17/II 1983

После переработки

$23 / \mathrm{V} 1983$

V. PLATONOV, O. KLJAVINA, L. IVLEVA

\section{KIVISOE UTTETORVA \\ NEUTRAALSETE HAPNIKUOHENDITE STRUKTUUR}

Neutraalsed hapnikuühendid on keeruline paljukomponentne erinevate ühendite segu, millel on alküleeritud hüdroaromaatne või täielikult hüdreeritud skelett.

Individuaalühendid on eraldatud ekstraheerimise ja õhukese kihi kromatograafia abil; nende iseloomustamiseks on kasutatud IP-, UV- ja TMR-spektroskoopiat, kromatomassispektromeetriat, elemendi- ja funktsionaalanalüüsi ning kvalitatiivseid reaktsioone.

On määratud uuritud ühendite molekulmass ning esitatud tsükloheksaani ekstrakti heksaani eluaadi ja kloroformi ekstrakti ühendite oletatavad struktuurivalemid. 


\section{THE STRUCTURE OF NEUTRAL OXYGEN-CONTAINING COMPOUNDS OF PRIMARY COAL TARS}

It is shown that the neutral oxygen-containing compounds represent a complex mixture of different-class substances with an alkyl-hydroaromatic or perhydrogenated nucleus which contains phenol-, ether-, chinoid-, ester-, carbonyl-, alcohol-groups and oxygen- or nitrogen-containing heterocycles.

Individual compounds were isolated by extraction and thin-layer chromatography.

The studied compounds are characterized by IR-, UV-, and NMR-spectroscopy, chromato-mass-spectrometry, routine and functional analysis, specific analytical reactions and determination of molecular weight.

Structural formulas are proposed for the components of hexane-eluate and chloroform extract. 